
\title{
28 Research Square \\ Removal of COD in Wastewater By Magnetic Coagulant Prepared From Modified Fly Ash
}

\section{Wen Wang ( $\nabla$ wangwen809@163.com )}

North China Electric Power University

\section{Liqiang Qi}

North China Electric Power University - Baoding Campus https://orcid.org/0000-0001-6039-1224

\section{Pan Zhang}

North China Electric Power University - Baoding Campus

Jichen Luo

North China Electric Power University - Baoding Campus

\section{Jingxin Li}

North China Electric Power University - Baoding Campus

\section{Research Article}

Keywords: Fly ash, Acid-base modification, Mixed magnetic, Coagulant, COD, Kinetic

Posted Date: December 6th, 2021

DOI: https://doi.org/10.21203/rs.3.rs-1078441/v1

License: (c) (i) This work is licensed under a Creative Commons Attribution 4.0 International License. Read Full License

Version of Record: A version of this preprint was published at Environmental Science and Pollution Research on March 8th, 2022. See the published version at https://doi.org/10.1007/s11356-022-19540-0. 


\section{Abstract}

In order to investigate the effective method of COD removal from desulfurization wastewater, acidmodified fly ash (AFA) and base-modified fly ash (BFA) were prepared by impregnation method. Then, magnetic coagulants (Fe-AFA, Fe-BFA) were prepared by mixing the modified fly ash with magnetic components. The structural characterization results showed that the specific surface area and the porosity of fly ash were obviously increased after modification. Fe-AFA magnetic coagulant has the best performance and superparamagnetism. Under the same experimental conditions, the maximum COD removal amounts of FA, BFA, AFA, Fe-BFA and Fe-AFA were 2.180, 3.209, 4.631, 3.710 and $5.687 \mathrm{mg} / \mathrm{g}$, respectively. The COD removal amount of Fe-AFA was increased by $112.43 \%$ compared with the raw FA. The quasi-second-order kinetic and Langmuir equation could well fit the COD coagulation process of five coagulants. After five cycles, the COD removal amount of Fe-AFA was $2.735 \mathrm{mg} / \mathrm{g}$, and the removal rate still reached $67.53 \%$. These findings provide a feasible method for the treatment of fly ash from coal-fired power plants and the preparation of highly efficient COD trapping magnetic coagulants.

\section{Introduction}

With the deepening of industrialization and urbanization, the increasingly prominent problem of water pollution has become a constraint on the social and economic development of China (Gao 2018). The COD value as one of the important indicators to evaluate the sewage discharge, the higher the COD value, the more serious the water pollution. Without effective treatment, a large amount of organic pollutants can be adsorbed and deposited by the sediment, which can cause lasting toxicity on aquatic organisms within several years, and then damage to the ecological environment (Zhang et al. 2021; Wang et al. 2017).

Magnetic coagulation technology is currently one of the main technologies for treating desulfurization wastewater. This technology adds magnetic powder to the ordinary coagulation and sedimentation process, which makes coagulants, pollutants and magnetic powder flocculate together to form a high dense floc, thus improving the effect of coagulation and sedimentation. At the same time, the added magnetic powder can be recovered and recycled (Wang et al. 2016; Zhang et al. 2017). Extensive research has shown that the magnetic $\zeta$ potential on the surface of magnetic powder is negatively charged ( Amiralian et al. 2020; Scardigli et al. 2021), the positive ions generated by the aqueous solution of coagulant gather around the negatively charged colloidal particles and magnetic powder under the effect of electric neutralization. As the static electromagnetic force disappears, the colloidal particles and magnetic powder particles are aggregated under the effect of van der Waals force, and then the flocs are further agglomerated and enlarged by the adsorption bridging effect of flocculant, which finally makes the pollutants and water departed from wastewater (Lin et al. 2021; Hamoud, Finqueneisel and Azambre 2017; Sherman et al. 2019).

As the main solid contaminant wastes emitted from coal-fired power plants, fly ash often causes pollution to the surrounding environment without effectively disposed (Liu et al. 2018; Renew et al. 2021). 
The use of fly ash as adsorbent and flocculant in water treatment can effectively solve the recycling problem of solid waste from coal-fired power plants, and realize the sustainable use of resources (Swarnalakshmi et al. 2018; Trang, Ho and Babel 2021). The primitive fly ash has limited ability to remove pollutants. Therefore, the current research has focused on modification of fly ash, so as to improve its ability to remove pollutants from wastewater (Gao et al. 2021; Hussain et al. 2021). Chen et al. (2020) used $\mathrm{HCl}$ and $\mathrm{NaOH}$ for acid-base modification of fly ash to remove norfloxacin from water. The results showed that after the modification, the specific surface area of fly ash increased and the removal effect of norfloxacin was significantly enhanced. At the optimal reaction conditions, the maximum norfloxacin removal of acid-modified and base-modified fly ash were increased by $109 \%$ and $171 \%$, respectively. In order to obtain fly ash with better performance, two or more modification methods are usually combined to modify fly ash (Jin et al. 2018; Sroka et al. 2017; Teng, Zhang and Qi 2019). Qi et al. (2020) used base co-roasting to modify fly ash and applied it to the treatment of desulfurization wastewater, the results showed that when the adsorbent dosage of $10 \mathrm{~g} / \mathrm{L}$, the reaction $\mathrm{pH}=8.0$ and the reaction temperature of $333 \mathrm{~K}$, the removal rate of $\mathrm{Cl}^{-}$from simulated wastewater reached $68.1 \%$.

At present, much of the research on fly ash has been describe the removal of heavy metal and salt, while little published data on the removal of COD in water. In order to simplify the technological process of magnetic coagulation and reduce the cost, this study used $\mathrm{H}_{2} \mathrm{SO}_{4}$ and $\mathrm{NaOH}$ to modify fly ash with acid and base, and prepared a magnetic coagulant by mixed magnetic treatment. Through the characterization analysis and mixed magnetic treatment of coagulant, the removal mechanism of COD in water was studied, which provides a feasible method for the preparation of efficient COD-trapping magnetic coagulant, and a new insight for the treatment of COD wastewater by magnetic coagulation.

\section{Experimental Section}

\section{Experiment materials}

Reagents: glucose standard product (purity 99.9\%) was purchased from Aladdin Reagent (Shanghai) Co., Ltd.; $\mathrm{H}_{2} \mathrm{SO}_{4}, \mathrm{NaOH}$, and $\mathrm{NaCl}$ were all analytical pure.

Instruments: XCSQ50×70 magnetic separator (Jiangxi Hengcheng Mineral Processing Equipment Co., Ltd., China); 6B-12 COD intelligent digestion instrument, 6B-80 intelligent water quality analyzer (Jiangsu Shengaohua Environmental Protection Co., Ltd., China); H1850 high-speed desktop centrifuge (Shanghai Anting Scientific Instrument Factory, China); PHS-3C pH measuring instrument (Shanghai Precision Scientific Instrument Co., Ltd., China), HZQ-X300C porous physisorption apparatus (Beishide Instrument Technology Co.,Ltd., China) SS-550 scanning electron microscope (Shimadzu Corporation, Japan). IRTracer-100 infrared spectrum (Shimadzu Corporation, Japan); 250XI X-ray photoelectron spectrometer (Thermo ESCALAB, USA); SQUID-VSM magnetic measurement system (Quantum Design, USA).

\section{Selection of original fly ash}


The original fly ash used in this experiment is taken from a power plant in North China, and the chemical composition of the original fly ash is shown in Table 1.

Table 1

Chemical composition of fly ash

\begin{tabular}{|lcccccccc|}
\hline Compound & $\mathrm{SiO}_{2}$ & $\mathrm{Fe}_{2} \mathrm{O}_{3}$ & $\mathrm{Al}_{2} \mathrm{O}_{3}$ & $\mathrm{CaO}$ & $\mathrm{K}_{2} \mathrm{O}$ & $\mathrm{MgO}$ & $\mathrm{MnO}$ & Others \\
\hline Content(\%) & 54.1 & 17.5 & 11.6 & 11.3 & 1.18 & 0.192 & 0.126 & 4.002 \\
\hline
\end{tabular}

What stands out in the table is the content of $\mathrm{SiO}_{2}, \mathrm{Fe}_{2} \mathrm{O}_{3}$ and $\mathrm{Al}_{2} \mathrm{O}_{3}$ in the original fly ash is as high as $83.2 \%$. As fly ash contains a large number of irregular and closed pores, there are a large number of $\mathrm{Si}$ and $\mathrm{Al}$ active points. The active using $\mathrm{Al}$ and $\mathrm{Si}$ in fly ash can be released by chemical modification, which can not only generate compounds with flocculation effect, but also increase its specific surface area, so that fly ash has both flocculation and adsorption in solution.

\section{Coagulant preparation}

Magnetic fly ash: Firstly, put the dried original fly ash into the magnetic separator and scan the fly ash under strong magnetic field to obtain magnetic fly ash with iron grade more than $30 \%$. Subsequently, the magnetic fly ash was ball milled and then magnetically sorted in a weak magnetic field to remove the strongly magnetic fly ash with an iron grade greater than $40 \%$, and finally obtain medium to strong magnetic fly ash with iron grade between $30 \%$ and $40 \%$. The magnetic fly ash obtained by magnetic separation was marked as Fe.

Fly ash: Take the non-magnetic fly ash remaining in the strong magnetic field, and through 200 mesh to obtain the non-magnetic fly ash, which was sealed and stored for later use. The sample was marked as FA.

Base modified fly ash: Prepare $2.0 \mathrm{~mol} / \mathrm{L} \mathrm{NaOH}$ solution, mixed it with FA according to a solid-liquid ratio of $1: 3$, stirred continuously electrically at $298 \mathrm{~K}$ in a constant temperature water bath at $80 \mathrm{r} / \mathrm{min}$ for 30 min, filtered, dried, ground and set aside. The sample was marked as BFA.

Acid modified fly ash: Prepare $2.0 \mathrm{~mol} / \mathrm{L} \mathrm{H}_{2} \mathrm{SO}_{4}$ solution, mixed with $\mathrm{FA}$ according to the ratio of solidliquid ratio of $1: 3$, and add $1.0 \mathrm{~g} \mathrm{NaCl}$, other operations were the same as BFA preparation process. The sample was marked as AFA.

Mixed magnetic base modified fly ash: Fully mix the BFA with Fe in the ratio of $10: 3$ to obtain the magnetic coagulant. The sample was marked as Fe-BFA.

Mixed magnetic acid modified fly ash: Fully mix the AFA with Fe in the ratio of 10:3 to obtain the magnetic coagulant. The sample was marked as Fe-AFA.

\section{Characterization of coagulants}


The specific surface area and pore volume of coagulants were determined by porous physisorption apparatus (EVO) (Li et al. 2020). The scanning electron microscopy energy dispersive spectroscopy analysis (SEM-EDS), Fourier Transform infrared spectroscopy (FTIR) and X-ray photoelectron spectroscopy (XPS) were used to characterize the particle size distribution, microstructure morphology, functional groups and chemical state of coagulants, respectively (Lee et al. 2021; Abdelmaksoud et al. 2021; Lee et al. 2021). A physical property measurement system-vibrating sample magnetometer (PPMSVSM) was used to measure the magnetism of coagulants (Dennis et al. 2015; Li et al. 2020).

\section{Experimental design}

$10.00 \mathrm{~g}$ of FA, BFA, AFA, Fe-BFA and Fe-AFA were taken into $250 \mathrm{~mL}$ conical flasks, and $100 \mathrm{~mL}$ of simulated wastewater with COD concentration of $400 \mathrm{mg} / \mathrm{L}$ was added. The initial $\mathrm{pH}$ of the solution was adjusted to $7.0 \pm 0.2$ and the test temperature was $298 \mathrm{~K}$. After shaken and stirred for $60 \mathrm{~min}$, the samples were taken at $0,1,3,5,10,15,30,45,60,120,240$ and $360 \mathrm{~min}$, respectively, to study the coagulation kinetic process. COD concentration of $100,200,300,400,500,600,700,800,900$ and $1000 \mathrm{mg} / \mathrm{L}$, respectively, to study the coagulation isothermal process. On the basis of coagulation isothermal experiments, the temperature was assessed at 288,298 , and $308 \mathrm{~K}$, respectively, to study the coagulation thermodynamic process. Repeatability experiments were performed five times. After shaking and stirring for $60 \mathrm{~min}$, the solution was left for $60 \mathrm{~min}$ and the COD concentration of the upper clear layer was measured.

All the above experiments were performed with 3 groups of duplicates, and the data were fitted and analyzed using Origin.

\section{Data analysis processing}

\section{Removal amount}

Eq. (1) is the calculation formula of COD removal amounts $Q_{t}$ at time $t$.

$Q_{\mathrm{t}}=\frac{\left(C_{0}-C_{t}\right) V}{m}$

Where $C_{0}$ and $C_{t}$ are the mass concentration of COD in the flocculation system at the initial and time $\mathrm{t}$, respectively, $\mathrm{mg} / \mathrm{L} ; V$ is the volume, $\mathrm{L} ; m$ is the sample weight, $\mathrm{g}$.

\section{Coagulation kinetic analysis}

The coagulation kinetics experiments were fitted and analyzed by the quasi-first-order kinetic equation (2) and quasi-second-order kinetic equation (3).

$\frac{d Q_{t}}{d t}=k_{1}\left(Q_{e}-Q_{t}\right)$ 
$\frac{d Q_{t}}{d t}=k_{2}\left(Q_{e}-Q_{t}\right)^{2}$

Where $Q_{e}$ is the removal amounts of COD at equilibrium, $\mathrm{mg} / \mathrm{g} ; \mathrm{k}_{1}$ is the quasi-first-order rate constant, $\mathrm{h}^{-1} ; k_{2}$ is the quasi-second-order rate constant, $\mathrm{g} /(\mathrm{mg} \cdot \mathrm{h})$.

\section{Coagulation isothermal analysis}

The isothermal experiments were performed by fitting the data with Freundlich equation (4) and Langmuir equation (5) to analyze the removal process of COD by FA, BFA, AFA, Fe-BFA and Fe-AFA. The equations are as follows.

$\ln Q_{e}=\ln K_{f}+\frac{1}{n} \ln C_{e}$

$\frac{1}{Q_{\mathrm{e}}}=\frac{1}{Q_{m}}+\frac{1}{K_{L} Q_{m} C_{e}}$

Where $C_{e}$ is the mass concentration of COD in the solution system at equilibrium, $\mathrm{mg} / \mathrm{L} ; K_{f}$ is the Freundlich equilibrium constant; $n$ represents the constant of reaction strength; $Q_{m}$ is the theoretical maximum removal, $\mathrm{mg} / \mathrm{g} ; K_{L}$ is the affinity coefficient, $\mathrm{L} / \mathrm{mg}$.

\section{Thermodynamic analysis of coagulation}

The Gibbs free energy equations (6) and (7) were used to calculate the thermodynamic parameters (enthalpy change $\Delta \mathrm{H}$, entropy change $\Delta \mathrm{S}$ ) of the coagulation process and analyze the effect of temperature on COD removal.

$\Delta \mathrm{G}=-\mathrm{R} \operatorname{Tln} \mathrm{K}(6)$

$\Delta \mathrm{G}=\Delta \mathrm{H}-\mathrm{T} \Delta \mathrm{S}(7)$

Where $\Delta G$ is the Gibbs free energy change, $\mathrm{kJ} / \mathrm{mol} ; K$ is the thermodynamic equilibrium constant, which can be fitted by the Langmuir equation, $\mathrm{L} / \mathrm{mol} ; R$ is the ideal gas constant, $8.314 \mathrm{~J} /(\mathrm{mol} \cdot \mathrm{K}) ; T$ is the reaction temperature, $\mathrm{K} ; \Delta H$ is the standard enthalpy change, $\mathrm{kJ} / \mathrm{mol} ; \Delta S$ is the standard entropy change, $\mathrm{kJ} /(\mathrm{mol} \cdot \mathrm{K})$; make a relation straight line of $\Delta G T$, whose slope and intercept correspond to the values of $\Delta S$ and $\Delta H$, respectively.

\section{Results And Discussion}

\section{Characterization analysis of coagulant}

BET specific surface area and pore volume analysis 
Table 2

Specific surface area and pore volume analysis

\begin{tabular}{|lll|}
\hline Sample & Specific surface area $\left(\mathrm{m}^{2} / \mathbf{g}\right)$ & Pore volume $\left(\mathrm{cm}^{3} / \mathbf{g}\right)$ \\
\hline FA & 2.220 & 0.004 \\
\hline BFA & 11.767 & 0.011 \\
\hline AFA & 22.218 & 0.016 \\
\hline Fe-BFA & 20.325 & 0.018 \\
\hline Fe-AFA & 28.636 & 0.022 \\
\hline
\end{tabular}

Table 2 shows the specific surface area and pore volume of FA, BFA, AFA, Fe-BFA and Fe-AFA. What stands out in the table is the specific surface area and the porosity of fly ash were obviously increased after modification. The specific surface areas of BFA and AFA were 11.767 and $22.218 \mathrm{~m}^{2} / \mathrm{g}$, respectively, which were 4.30 and 9.01 times higher than FA, and the pore volume were 1.75 and 3.00 times that of FA. However, in comparison, the specific surface area and pore volume of the AFA were better than that of the BFA, which indicated that acid modification was more helpful to the formation of pore structure. The specific surface areas of the coagulants were increased further after mixing magnetization, and the specific surface areas of Fe-BFA and Fe-AFA were 20.325 and $28.636 \mathrm{~m}^{2} / \mathrm{g}$, respectively.

\section{SEM and EDS energy spectrum analysis}

Figure 1 shows the SEM images of FA, BFA, AFA, Fe-BFA and Fe-AFA. It can be seen from Figure 1 that the surface of FA was smoothly and the specific surface area was small. After the modification, due to the corrosive effect of $\mathrm{NaOH}$ and $\mathrm{H}_{2} \mathrm{SO}_{4}$, the original surface morphology of fly ash was greatly changed. The surface of BFA and AFA was rougher than FA, and the specific surface area and porosity have been significantly improved. Moreover, compared with BFA, the surface of AFA was rougher and more porous, and the surface was corroded to a greater extent. After the addition of magnetic powder, a large number of particles were attached to the surface of Fe-BFA and Fe-AFA, which made the surface of the coagulant show "flocculence". and the coagulants porosity were more abundant.

In order to analyze whether the particles attached to the surface of Fe-BFA and Fe-AFA are doped magnetic powders, EDS analysis was used to determine the elements of the coagulants. The Fig. 2 and Table 3 shows the EDS spectra and elemental normalized mass percentage of FA, BFA, AFA, Fe-BFA and Fe-AFA, respectively. From Fig. 2 and Table 3, it can be seen that the five coagulants are mainly based on $\mathrm{O}, \mathrm{Al}$ and Si elements. The absorption peaks of Fe element only appeared in the EDS energy spectra of FeBFA and Fe-AFA, while the content of Fe element in FA, BFA and AFA did not reach the detection limit of the instrument, and it was tentatively inferred that the magnetic powder successfully adhered to the surface of fly ash after acid-base modification. Another important finding was that after acid-base impregnation, the FA reacted chemically with the acid-base solution, which leads to a reduction of 0 element content in the modified fly ash. 
Table 3

The normalized mass percentage of elements (wt\%) of FA, BFA, AFA, Fe-BFA and Fe-AFA

\begin{tabular}{|llllllll|}
\hline Sample & $\mathbf{C}$ & $\mathbf{0}$ & $\mathbf{A l}$ & $\mathbf{S i}$ & $\mathbf{K}$ & $\mathrm{Fe}$ & Others \\
\hline FA & 5.34 & 33.86 & 24.40 & 30.58 & 1.53 & not detected & 4.29 \\
\hline BFA & 5.16 & 28.72 & 31.53 & 29.36 & 1.27 & not detected & 4.96 \\
\hline AFA & 5.97 & 25.23 & 31.74 & 29.19 & 1.22 & not detected & 6.65 \\
\hline Fe-BFA & 4.75 & 26.25 & 30.73 & 28.11 & 1.01 & 3.23 & 5.92 \\
\hline Fe-AFA & 5.05 & 23.59 & 30.25 & 27.90 & 0.92 & 3.77 & 8.52 \\
\hline
\end{tabular}

\section{FTIR analysis}

The changes of the main functional groups of the coagulant before and after the modification were analyzed by FTIR. Fig. 3 shows the FTIR spectra of FA, BFA, AFA, Fe-BFA and Fe-AFA. As can be seen in Fig. 3 , the five coagulants showed distinctive peaks near $1095 \mathrm{~cm}^{-1}$ and $464 \mathrm{~cm}^{-1}$, which were identified as $\mathrm{Si}-\mathrm{O}$ bending vibration and stretching vibration peaks (Liu et al. 2020). The adsorption peak at 800 $\mathrm{cm}^{-1}$ is assigned to the Si-O-Si stretching vibration peak, and the adsorption peak at $557 \mathrm{~cm}^{-1}$ is assigned to the Al-O stretching vibration peak (Wang et al. 2015).

Compared with the FTIR of the FA, the intensity of the characteristic peaks of the Si-O and $\mathrm{Al}-\mathrm{O}$ bonds in BFA and AFA were significantly weakened after the modification. It indicated that the modification produced changes to the chemical structure of the fly ash, and the Si-O and Al-O bonds in the FA were broken, which led to decrease of response values. Compared with BFA, the characteristic peak response values of AFA were further reduced. This results was shown that the acid modification contributed more to the breakage of $\mathrm{Si}-\mathrm{O}$ and $\mathrm{Al}-\mathrm{O}$ bonds, which made the acid-modified coagulant have stronger coagulation and adsorption ability. It can also be seen from Fig. 3 that after the modification, the Si-O-Si, $\mathrm{Si}-\mathrm{O}$, and Al-O bond were redshifted to different degrees. The reason for this result is that the acid-base modification will have a corrosive effect on the fly ash, which leads to the expansion of Si-O, Al-O and SiO-Si bonds to different degrees, and an increase in the crystal spacing. Therefore, the van der Waals and intermolecular forces were reduced and the absorption peaks were shifted to the long wavelength direction (Jhang et al. 2017). Compared with BFA and AFA, the characteristic peaks of Fe-BFA and Fe-AFA after mixing magnetization did not change much, indicated that the mixing magnetization only changed the physical properties of fly ash and did not change the chemical structure of fly ash.

\section{XPS analysis}

Figure 4 shows the XPS spectra of FA, BFA, AFA, Fe-BFA and Fe-AFA. It can be seen from Figure 4(a) that the characteristic peaks of $01 \mathrm{~s}, \mathrm{C} 1 \mathrm{~s}, \mathrm{Si} 2 \mathrm{p}$ and $\mathrm{Al} 2 \mathrm{p}$ appeared in the five kinds of coagulants. Due to the erosion effect of $\mathrm{NaOH}$ and $\mathrm{H}_{2} \mathrm{SO}_{4}$, the intensity of the $01 \mathrm{~s}$ characteristic peaks on the BFA and AFA was significantly weakened, which was the same as that determined by EDS in 3.1.2. After the mixing of 
modified fly ash, both Fe-BFA and Fe-AFA had Fe2p characteristic peaks on the XPS curves, which indicated that the magnets had been successfully mixed with fly ash. The Fe2p characteristic peaks on Fe-BFA and Fe-AFA were further analyzed, and Figure 4(b) showed the fine mapping of the Fe2p region. The peak values of $\mathrm{Fe} 2 \mathrm{p}_{3 / 2}$ and $\mathrm{Fe} 2 \mathrm{p}_{1 / 2}$ in Figure $4(\mathrm{~b})$ are 712.4 and $725.8 \mathrm{eV}$, respectively, which coincided with the $\mathrm{Fe} 2 \mathrm{p}$ peak in $\mathrm{Fe}_{3} \mathrm{O}_{4}$ standard (Im et al. 2015). Further analysis showed that the magnetic material in Fe-BFA and Fe-AFA was $\mathrm{Fe}_{3} \mathrm{O}_{4}$.

\section{Magnetization intensity analysis}

Figure 5 shows the variation curves of magnetization intensity with magnetic field for FA, BFA, AFA, FeBFA and Fe-AFA. The VSM curves showed that the magnetization intensity of Fe-BFA and Fe-AFA increased with the increase of magnetic field, and the magnetization intensity finally reached the saturation values of $10.38 \mathrm{emu} / \mathrm{g}$ and $12.46 \mathrm{emu} / \mathrm{g}$. Both Fe-BFA and Fe-AFA exhibited superparamagnetism ( $\mathrm{Li}$ et al. 2020). Since FA, BFA and AFA were magnetically separated, the change of VSM curve were not obvious, and the saturation values of magnetization were 1.56, 1.42, and 1.29 emu/g, respectively. It can be seen from Figure 5 that the prepared Fe-BFA and Fe-AFA magnetic coagulants have higher magnetic induction intensity after magnetic mixing.

\section{Coagulation kinetic analysis}

Figure 6 shows the curves of COD removal by FA, BFA, AFA, Fe-BFA and Fe-AFA with time. When the coagulant dosage was $100 \mathrm{~g} / \mathrm{L}$ and the initial concentration of COD was $400 \mathrm{mg} / \mathrm{L}$, the coagulation kinetic processes of FA, BFA, AFA, Fe-BFA and Fe-AFA on COD were divided into a rapid phase and an equilibrium phase. Within 0-30 min, which is the rapid coagulation stage, the removal of COD by all five coagulants exceeded $70 \%$ of the total removal, reaching $1.180,1.475,2.451,2.425$ and $3.527 \mathrm{mg} / \mathrm{g}$, respectively. Among them, when the coagulation time was $30 \mathrm{~min}$, the coagulation system of Fe-AFA to COD reached equilibrium. After 30 min of reaction time, the removal rates of COD by FA, BFA, AFA and FeBFA gradually slowed down. Among them, FA and BFA reached equilibrium after 120 min of reaction, and the equilibrium removal amounts of COD were $1.665 \mathrm{mg} / \mathrm{g}$ and $2.039 \mathrm{mg} / \mathrm{g}$. The equilibrium coagulation time of AFA and Fe-BFA was 60 min, and the removal amounts of COD at equilibrium were $2.786 \mathrm{mg} / \mathrm{g}$ and $2.582 \mathrm{mg} / \mathrm{g}$, respectively. The results of the coagulation kinetic analysis were shown that the coagulant removal of COD can be further improved and the flocculation time shortened by mixing magnetic operation of the modified fly ash.

The coagulation kinetics experiment clearly demonstrates the significant change of the COD removal amounts after modification. This was due to the corrosive effect of base and acid, which increased the surface defects of fly ash, enriched the porosity, and increased the specific surface area. Therefore, the coagulation provided more adsorption sites, and the adsorption capacity were enhanced, which makes more COD enriched on the surface of coagulations and removed by sedimentation through the coagulation process (Wang et al. 2020). The magnetic mixing operation of the modified fly ash can further improve the coagulant's ability to remove COD and greatly reduce the time required for flocculation reaction. The coagulant Fe-AFA, prepared by acid modification of fly ash followed by mixing 
magnetic process, showed the best removal effect. The removal of COD by Fe-AFA was increased $111.83 \%$ higher than that of FA, and the time to reach the best coagulation effect was shortened by 4 times.

The coagulation kinetics of COD removal by FA, BFA, AFA, Fe-BFA and Fe-AFA were fitted using quasi-firstorder and quasi-second-order kinetic equations, respectively. The correlation parameters were shown in Table 4. It is apparent from this table that the quasi-second-order kinetic equation model fitted well for the five coagulants to remove COD. The $R^{2}$ values of the fitted equations for FA, BFA, AFA, Fe-BFA and Fe-AFA were $0.9118,0.8873,0.9410,0.9375$ and 0.9417 , respectively, which reached the highly significant correlation level. In summary, these results show that the quasi-second-order kinetic equations can better fitted the coagulation kinetic processes of FA, BFA, AFA, Fe-BFA and Fe-AFA on COD. Therefore, it was inferred that the process of COD removal by the five coagulants was not a single flocculation reaction, but the result of multiple mechanisms (such as surface adsorption, chemisorption, coagulation and precipitation, etc.) acting simultaneously (Folens et al. 2017).

Table 4

Coagulation kinetic fitting parameters of COD removal by FA, BFA, AFA, FeBFA and Fe-AFA

\begin{tabular}{|lllllll|}
\hline Sample & \multicolumn{2}{l}{ Quasi-first-order kinetic } & \multicolumn{3}{c|}{ Quasi-second-order kinetic } \\
\cline { 2 - 7 } & $\boldsymbol{Q}_{\boldsymbol{e}, 1}$ & $\boldsymbol{k}_{\boldsymbol{1}}$ & $\boldsymbol{R}^{2}$ & $\boldsymbol{Q}_{\boldsymbol{e}, 2}$ & $\boldsymbol{k}_{\mathbf{2}}$ & $\boldsymbol{R}^{2}$ \\
\hline FA & 1.623 & 0.0558 & $0.8856^{* *}$ & 1.761 & 0.0472 & $0.9118^{\star *}$ \\
\hline BFA & 1.952 & 0.0670 & $0.8424^{* *}$ & 2.111 & 0.0480 & $0.8873^{* *}$ \\
\hline AFA & 2.689 & 0.1441 & $0.9033^{* *}$ & 2.868 & 0.0768 & $0.9410^{* *}$ \\
\hline Fe-BFA & 2.518 & 0.1835 & $0.9102^{* *}$ & 2.661 & 0.1105 & $0.9375^{* *}$ \\
\hline Fe-AFA & 3.472 & 0.2915 & $0.9373^{* *}$ & 3.643 & 0.1306 & $0.9417^{* *}$ \\
\hline Note: ** indicates extremely significant correlation $(\mathrm{p} \leq 0.001)$. & \\
\hline
\end{tabular}

Figure 7 shows the curves of COD removal by FA, BFA, AFA, Fe-BFA and Fe-AFA with the initial concentration at $298 \mathrm{~K}$. When the coagulant addition was $100 \mathrm{~g} / \mathrm{L}$, the COD removal amounts of five coagulants showed a trend of increasing with the initial concentration and finally reached saturation. The maximum COD removal amounts of five coagulants were 2.180, 3.209, 4.631, 3.710 and $5.687 \mathrm{mg} / \mathrm{g}$, respectively, and the removal capacity were order by Fe-AFA $>A F A>F e-B F A>B F A>F A$. After modification by $\mathrm{NaOH}$ and $\mathrm{H}_{2} \mathrm{SO}_{4}$, the maximum removal of COD by BFA and AFA increased by $47.20 \%$ and $112.43 \%$, respectively. Moreover, through the magnetic mixing operation of the modified flocculant, the COD removal ability of the new flocculant is further enhanced. Compared with FA, the removal of COD by Fe- 
BFA and Fe-AFA has increased by $70.18 \%$ and $160.87 \%$, respectively. The experimental results showed that the new coagulant prepared from fly ash by acid-base modification and mixing magnetic process could significantly improve the removal ability of COD. Li et al. (2017) also showed that acid-base modification of biochar from potato stem and leaf could improve its adsorption capacity for sulfathiazole.

The coagulation isothermal of COD removal by FA, BFA, AFA, Fe-BFA and Fe-AFA were fitted using Freundlich and Langmuir equations, respectively, and the specific parameters are shown in Table 5. The fitted correlation coefficient $R^{2}$ values of the Langmuir equation for FA, BFA, AFA, Fe-BFA and Fe-AFA were $0.8857,0.9703,0.9876,0.9660$ and 0.9794 , respectively, which were higher than the fitted values of the Freundlich equation and showed good correlation. The isothermal curve of coagulation in Fig. 7 also showed that the Langmuir model curve fits better with the measured values, so the Langmuir equation can better reflect the COD removal process of the five coagulants at $298 \mathrm{~K}$. The correlation coefficients $R^{2}$ has reached a extremely significant correlation. This indicated that the COD removal process of the five coagulants mainly occurs in the single molecular layer on the surface of fly ash (Zhu et al. 2018), and the number of adsorption sites on the surface of coagulants determines the strength of their removal ability of COD. In the Langmuir equation, $K_{L}$ represented the affinity constant, and the larger the value, the stronger the removal capacity of the coagulant for the pollutant (Wang et al. 2019). In Table 5, the $K_{L}$ values of the five coagulants were $0.0041,0.0045,0.0075,0.0070$, and 0.0232 , respectively, and the $K_{L}$ value obtained by Fe-AFA fitting was the highest and the theoretical removal capacity is the strongest, which was consistent with the results of isothermal experiment. The $K_{L}>0$, indicated that the COD removal process of five coagulants can be carried out spontaneously at room temperature (Graouerbacart, Sayen and Guillon 2015).

Table 5

Coagulation isotherm fitting parameters of COD removal by FA, BFA, AFA, Fe-BFA and Fe-AFA

\begin{tabular}{|c|c|c|c|c|c|c|c|}
\hline \multirow[t]{2}{*}{ Sample } & \multirow[t]{2}{*}{$T / \mathrm{K}$} & \multicolumn{3}{|c|}{ Freundlich } & \multicolumn{3}{|l|}{ Langmuir } \\
\hline & & $K_{f}$ & $n$ & $R^{2}$ & $Q_{m}(\mathrm{mg} / \mathrm{g})$ & $K_{L}(\mathrm{~L} / \mathrm{mg})$ & $R^{2}$ \\
\hline FA & 298 & 0.1267 & 2.243 & $0.7725^{\star \star}$ & 3.091 & 0.0041 & $0.8857^{\star \star}$ \\
\hline BFA & 298 & 0.1664 & 2.120 & $0.8988^{\star *}$ & 4.555 & 0.0045 & $0.9703^{* *}$ \\
\hline AFA & 298 & 0.3497 & 2.331 & $0.9246^{\star *}$ & 6.091 & 0.0075 & $0.9876^{* \star}$ \\
\hline Fe-BFA & 298 & 0.2949 & 2.436 & $0.8736^{\star *}$ & 4.810 & 0.0070 & $0.9660^{\star \star}$ \\
\hline Fe-AFA & 298 & 0.9632 & 3.188 & $0.8461^{\star \star}$ & 6.565 & 0.0232 & $0.9794^{\star \star}$ \\
\hline
\end{tabular}

\section{Coagulation thermodynamic analysis}


Table 6 shows the coagulation thermodynamic fitting parameters of COD removal by FA, BFA, AFA, FeBFA and Fe-AFA at different temperatures. The Gibbs free energy change $\triangle G$ of FA, BFA, AFA, Fe-BFA and Fe-AFA at different temperatures were less than 0 , consequently indicating spontaneous coagulation (Zhai and Li 2019). The enthalpy change values of FA, BFA, AFA, Fe-BFA and Fe-AFA are 24.26, 11.98, $11.46,33.60$ and $25.26 \mathrm{~kJ} / \mathrm{mol}$, respectively. On the one hand, with $\Delta H>0$, indicated that their coagulation process is an endothermic process. On the other hand, the $|\Delta H|<40 \mathrm{~kJ} / \mathrm{mol}$, suggested that the coagulation process of COD was occured through van der Waals forces and hydrogen bonding (Taha et al. 2021). The entropy change values $\Delta S$ of the five coagulants were all greater than 0 , indicated that the removal of COD by coagulants was an irreversible process (Toumi et al. 2015). In summary, the COD removal of FA, BFA, AFA, Fe-BFA and Fe-AFA was a spontaneous, endothermic and irreversible process.

Table 6

Thermodynamic parameters of COD removal by FA, BFA, AFA, Fe-BFA and Fe-AFA

\begin{tabular}{|c|c|c|c|c|c|}
\hline Sample & $\begin{array}{l}T \\
/ \mathrm{K}\end{array}$ & $\begin{array}{l}K_{L} \\
/ \mathrm{L} \cdot \mathrm{mol}^{-1}\end{array}$ & $\begin{array}{l}\Delta G \\
/ \mathrm{kJ} \cdot \mathrm{mol}^{-1}\end{array}$ & $\begin{array}{l}\Delta H \\
/ \mathrm{kJ} \cdot \mathrm{mol}^{-1}\end{array}$ & $\begin{array}{l}\Delta S \\
/ \mathrm{kJ} \cdot \mathrm{mol}^{-1} \cdot \mathrm{K}^{-1}\end{array}$ \\
\hline \multirow[t]{4}{*}{ FA } & 288 & 522.46 & -14.99 & 24.26 & 0.136 \\
\hline & 298 & 738.66 & -16.36 & & \\
\hline & 308 & 1008.90 & -17.71 & & \\
\hline & 288 & 756.67 & -15.87 & 11.98 & 0.096 \\
\hline \multirow[t]{3}{*}{ BFA } & 298 & 810.72 & -16.59 & & \\
\hline & 308 & 1044.93 & -17.80 & & \\
\hline & 288 & 1297.15 & -17.16 & 11.46 & 0.099 \\
\hline \multirow[t]{2}{*}{ AFA } & 298 & 1351.20 & -17.86 & & \\
\hline & 308 & 1765.57 & -19.14 & & \\
\hline \multirow[t]{3}{*}{ Fe-BFA } & 288 & 900.80 & -16.29 & 33.60 & 0.172 \\
\hline & 298 & 1261.12 & -17.69 & & \\
\hline & 308 & 2233.98 & -19.75 & & \\
\hline \multirow[t]{3}{*}{ Fe-AFA } & 288 & 2756.45 & -18.97 & 25.26 & 0.153 \\
\hline & 298 & 4179.71 & -20.66 & & \\
\hline & 308 & 5476.86 & -22.04 & & \\
\hline
\end{tabular}

\section{Repeatability test analysis of coagulants}


Figure 8 shows the effect of recovery times on COD removal efficiency by FA, BFA, AFA, Fe-BFA and FeAFA. When the coagulant dosage was all $100 \mathrm{~g} / \mathrm{L}$, and the initial concentration of COD was $400 \mathrm{mg} / \mathrm{L}$, the COD removal rates of FA, BFA, AFA, Fe-BFA and Fe-AFA decreased with the increase of the repetition times. At the first use, the COD removal rates of FA, BFA, AFA, Fe-BFA and Fe-AFA were $41.63 \%, 51.02 \%$, $70.05 \%, 64.78 \%$ and $87.92 \%$, respectively. After the 5 th recycling, the COD removal rates of the five coagulants were $16.69 \%, 27.20 \%, 48.31 \%, 45.64 \%$ and $68.37 \%$, respectively. The COD removal capacity of the five coagulants were order by Fe-AFA>AFA>Fe-BFA>BFA>FA. Due to the limited adsorption performance of fly ash, the removal capacity of COD was gradually reduced after several coagulations. Through acid-base modification of fly ash and mixed magnetic operation, the surface of the new coagulant Fe-AFA was rougher, the adsorption sites were increased, thus enhancing the adsorption and flocculation capacity of the coagulant (Wang et al. 2020). What is interesting about the data in Figure 8 is that the COD removal rate by Fe-AFA remained above $60 \%$ after five recycling.

\section{Conclusions}

In this paper, we have prepared five coagulants: FA, BFA, AFA, Fe-BFA and Fe-AFA. Through the acid-base modification, the Si-O-Si, Si-O and Al-O bonds on the FA surface were broken, and the specific surface area and pore volume were significantly increased. The specific surface area of BFA and AFA being 4.30 and 9.01 times that of FA, respectively. In addition, we successfully prepared magnetic coagulants Fe-BFA and Fe-AFA. After mixing the magnet, Fe existed in the form of $\mathrm{Fe}_{3} \mathrm{O}_{4}$ in the coagulant, and both Fe-BFA and Fe-AFA exhibited superparamagnetic.

The results of coagulation experiments showed that under the same experimental conditions, the removal ability of COD were order by Fe-AFA $>A F A>F e-B F A>B F A>F A$. The maximum COD removal amounts of $F A$, BFA, AFA, Fe-BFA and Fe-AFA were 2.180, 3.209, 4.631, 3.710 and $5.687 \mathrm{mg} / \mathrm{g}$, respectively, and the coagulation equilibrium times were $120 \mathrm{~min}, 120 \mathrm{~min}, 60 \mathrm{~min}, 60 \mathrm{~min}$ and $30 \mathrm{~min}$, respectively. After modified-mixed magnetic, the performance of coagulant on COD removal was significantly improved. FeAFA showed the best coagulation performance, the COD removal increased by $112.43 \%$ compared with $\mathrm{FA}$, and the time required for coagulation equilibrium was shortened by 3 times. The coagulation characterization showed that the quasi-secondary kinetic equation and the Langmuir isotherm equation could better fit the process of COD removal by coagulants, and the thermodynamic analysis showed that the process was spontaneous, heat-absorbing and disordered. Impressively, after five cycles, the COD removal amount of Fe-AFA was $2.735 \mathrm{mg} / \mathrm{g}$, and the removal rate still reached $67.53 \%$. Therefore, the coagulant Fe-AFA with highest specific surface area, stability and coagulation performance can be considered a good candidate for the removal of COD from desulfurization wastewater.

\section{Declarations}

Author contributions Wen Wang: Investigation, Formal analysis, Writing - original draft. Li-Qiang Qi: Conceptualization, Writing - review \& editing, Supervision, Funding acquisition. Pan Zhang: Data curation, Methodology. Ji-Chen Luo: Investigation, Formal analysis. Jing-Xin Li: Resources, Methodology. 
Funding This work was supported by Natural Science Foundation of Hebei Province [grant numbers B2019502067]; and the Fundamental Research Funds for the Central Universities [grant numbers 2020MS152].

Data availability Not applicable

Ethics approval and consent to participate Not applicable.

Consent to publish Not applicable.

Competing interests The authors declare no competing interests.

\section{References}

1. Amiralian N, Mustapi M, Hossain S, Wang C, Rowan A (2020) Magnetic nanocellulose: A potential material for removal of dye from water. J Hazard Mater 394:122571

2. Abdelmaksoud M, Mohamed A, Sayed A, Khairy S (2021) Physical properties of PVDF-GO/black-TiO nanofibers and its photocatalytic degradation of methylene blue and malachite green dyes. Environ Sci Pollut Res 28:613-30625

3. Chen JY, Zhang J, Wang W, Ma XL, Guo YX, Sun FY, Wang YJ (2020) Comparison of adsorption characteristics of acid-base modified fly ash to norfloxacin. Spectrosc Lett 53:416-429

4. Dennis CL, Krycka KL, Borchers JA, Desautels RD, Lierop JV, Huls NF, Jackson AJ, Gruettner C, Ivkov R (2015) Internal Magnetic Structure of Nanoparticles Dominates Time-Dependent Relaxation Processes in a Magnetic Field. Adv Funct Mater 25:4300-4311

5. Folens K, Huysman S, Hulle SV, Laing GD (2017) Chemical and economic optimization of the coagulation-flocculation process for silver removal and recovery from industrial wastewater. Separation \& Purification Technology 179:145-151

6. Gao HT, Liu JN, Song HL, Yang JK (2021) Research on brightening modification of molecular sieves coated fly ash based on alkaline melting hydrothermal method. Nordic Pulp and Paper Research Journal 7:1507-1515

7. Gao RW (2018) Analysis of Current Situation and Countermeasures of Water Pollution of China. Resources and Human Settlement Environment 11:44-45. http://doi.org/CNKI:SUN:GTJJ.0.2018-11013

8. Graouerbacart M, Sayen S, Guillon E (2015) Adsorption of enrofloxacin in presence of Zn(II) on a calcareous soil. Ecotoxicology \& Environmental Safety 122:470-476

9. Hamoud HI, Finqueneisel G, Azambre B (2017) Removal of binary dyes mixtures with opposite and similar charges by adsorption, coagulation/flocculation and catalytic oxidation in the presence of $\mathrm{CeO}_{2} / \mathrm{H}_{2} \mathrm{O}_{2}$ Fenton-like system. J Environ Manage 195:195-207

10. Hussain Z, Chang NJ, Sun Q, Xiang SM, Ayaz T, Zhang H, Wang HT (2021) Modification of coal fly ash and its use as low-cost adsorbent for the removal of directive, acid and reactive dyes. J Hazard 
Mater 3:126778

11. Im ME, Pham-Cong D, Kim JY, Choi HS, Kim JH, Kim JP, Kim J, Jeong SY, Cho CR (2015) Enhanced electrochemical performance of template-free carbon-coated iron(II, III) oxide hollow nanofibers as anode material for lithium-ion batteries. J Power Sources 284:392-399

12. Jhang JH, Zhou C, Dagdeviren OE, Hutchings GS, Schwarz UD, Altman El (2017) Growth of two dimensional silica and aluminosilicate bilayers on $\mathrm{Pd}(\mathrm{III})$ : from incommensurate to commensurate crystalline. Physical Chemistry Chemical Physics 19:14001-14011. http://doi.org/ 10.1016/j.jpowsour.2015.03.024

13. Jin HQ, Liu Y, Wang CY, Lei XH, Guo M, Cheng FQ, Zhang M (2018) Two-step modification towards enhancing the adsorption capacity of fly ash for both inorganic $\mathrm{Cu}(\mathrm{II})$ and organic methylene blue from aqueous solution. Environ Sci Pollut Res Int 25:36449-36461

14. Lee DN, Gwon K, Kim Y, Cho H, Lee S (2021) Immobilization of antibacterial copper metal-organic framework containing glutarate and 1,2-bis (4-pyridyl) ethylene ligands on polydimethylsiloxane and its low cytotoxicity. J Ind Eng Chem 102:135-145

15. Lee SX, Zhang M, Wang GH, Meng WQ, Zhang X, Wang D, Zhou Y, Wang ZH (2021) Characterization of polyvinyl alcohol/starch composite films incorporated with p-coumaric acid modified chitosan and chitosan nanoparticles: A comparative study. Carbohydr Polym 262:117930

16. Li RN, Wang ZW, Guo JL, Zhao XT, Li Y, Xie XY (2017) Adsorption performance of acid-base modified biomass carbon for sulfathiazole in water. Journal of Environmental Science 37:4119-4128

17. Li Y, Dang L, Yang H, Hu H (2020) Removal of elemental mercury in flue gas by Cu-Fe modified magnetosphere from coal combustion fly ash. Fuel 271:117668

18. Li ZJ, Ju Y, Yu BW, Wu XL, Lu HJ, Li YX, Zhou J, Guo XF, Zhang ZH, Lin J, Wang JQ, Wang SA (2020) Modulated synthesis and isoreticular expansion of Th-MOFs with record high pore volume and surface area for iodine adsorption. Chem Commun 56:6716-6718

19. Lin SM, Chang CY, Liauh CT, Wang WR (2021) Design of Harmonic AFM Probe Subjected to van der Waals Force in the Modified Couple Stress Theory. Mathematical Problems in Engineering 1:1-11

20. Liu XJ, Wang H, Liu LL (2018) Development and Utilization of Fly Ash Resources and Industrial Development. Inorganic Salt Industry 50:12-14

21. Liu YX, Zeng FG, Sun BL, Jia P (2020) XRD and FTIR study of different particle size particles of ancient fly ash. Spectroscopy and Spectral Analysis 40:130-134. http://doi.org/ CNKI:SUN:GUAN.0.2020-05-028

22. Qi LQ, Liu KY, Wang RT, Li JX, Zhang YJ, Chen L (2020) Removal of Chlorine lons from Desulfurization Wastewater by Modified Fly Ash Hydrotalcite. ACS Omega 5:31665-31672

23. Renew JE, Zhang W, Huang CH (2021) Mass transport release of heavy metal oxyanions from solidified/stabilized co-disposed flue gas desulfurization brine and coal fly ash monoliths. Environ Sci Pollut Res 28:29945-29957

24. Scardigli S, Berrilli F, Moro DD, Giovannelli L (2021) Luca Giovannelli. Stellar Turbulent Convection: The Multiscale Nature of the Solar Magnetic Signature Atmosphere. 12:938. 
https://doi.org/10.3390/atmos12080938

25. Sherman ZM, Pallone JL, Erb RE, Swan JW (2019) Enhanced diffusion and magnetophoresis of paramagnetic colloidal particles in rotating magnetic fields. Soft Matter 15:6677-6689

26. Sroka J, Rybak A, Sekula R, Filipczak P, Kozanecki M, Sitarz M (2017) Two-Step Procedure of Fly Ash Modification as an Alternative Method for Creation of Functional Composite. Journal of Polymers \& the Environment 25:1342-1347

27. Swarnalakshmi KS, Chinnaiyan P, Nivetha S, Nair AS (2018) Use of rice husk ash as an adsorbent to remove contaminants in water and comparison with advanced oxidation process - a study. Materials Today: Proceedings 5:24248-24257. https://doi.org/10.1016/j.matpr.2018.10.220

28. Taha A, Dana E, Hassanin HA (2021) Modified Activated Carbon-Loaded with Bio-Synthesized $\mathrm{Ag} / \mathrm{ZnO}$ Nanocomposite and Its Application for the Removal of $\mathrm{Cr}(\mathrm{VI})$ lons from Aqueous Solution. Surfaces and Interfaces 23:100928

29. Teng F, Zhang HY, Qi LQ (2019) The adsorption performance of microwave combined with alkali modified fly ash for $\mathrm{Cr}(\mathrm{VI})$. Mineral Resources Conservation and Utilization 39:26-31

30. Toumi LB, Hamdi L, Salem Z, Allia K (2015) Batch adsorption of methylene blue from aqueous solutions by untreated alfa grass. Desalination \& Water Treatment 53:806-817

31. Trang N, Ho N, Babel S (2021) Reuse of waste sludge from water treatment plants and fly ash for manufacturing of adobe bricks. Chemosphere 284:131367

32. Wang J, Liu LL, Yang J, Yang SS, Zhang HW, Jia H, Guo XF (2016) Using magnetic powder to enhance coagulation membrane filtration for treating micro-polluted surface water. Water Science \& Technology: Water Supply 16:104-114

33. Wang MX, Xu HJ, Xue YJ, Chang JT, Chen K, Pan WG (2017) Experimental study on COD treatment of calcium carbide slag desulfurization wastewater. Thermal Power Generation 46:64-70

34. Wang W, Ma XL, Sun J, Chen JY, Zhang J, Wang YJ, Wang JH, Zhang H (2019) Adsorption of enrofloxacin on acid/alkali-modified corn stalk biochar. Spectrosc Lett 52:367-375

35. Wang W, Zhang J, Chen TY, Sun J, Ma XL, Wang YJ, Zhang JH, Xie ZL (2020) Preparation of $\mathrm{TiO}_{2^{-}}$ modified Biochar and its Characteristics of Photo-catalysis Degradation for Enrofloxacin. Sci Rep 10:6588

36. Wang Z, Pan XM, He YH, Hu YM, Gu HS, Wang Y, Erten-Ela S (2015) Piezoelectric Nanowires in Energy Harvesting Applications. Advances in Materials Science \& Engineering 2015:1-21. https://doi.org/10.1155/2015/165631

37. Zhai QZ, Li XD (2019) Immobilization and sustained release of cefalexin on MCF nano-mesoporous material. J Dispers Sci Technol 40:1-11

38. Zhang J, Liu XX, Li YF, Chang XF, Zhang JJ, Chen G (2021) Study of COD Removal from the Waste Drilling Fluid and Its Application Chad Oilfield. Water Treatment and Demineralization Technology 43:60-67 
39. Zhang M, Xiao F, Wang DS, Xu XZ, Zhou Q (2017) Comparison of novel magnetic polyaluminum chlorides involved coagulation with traditional magnetic seeding coagulation: Coagulant characteristics, treating effects, magnetic sedimentation efficiency and floc properties. Sep Purif Technol 182:118-127

40. Zhu YT, Li YD, Wang MY, Ma XL, Zhang QP, Wang YJ (2018) Study on the characteristics of zinc adsorption on biochar prepared by alkalization of corn stover. Journal of Agro-Environment Science 37:179-185. http://doi.org/ 10.13671/j.hjkxxb.2017.0155

\section{Figures}
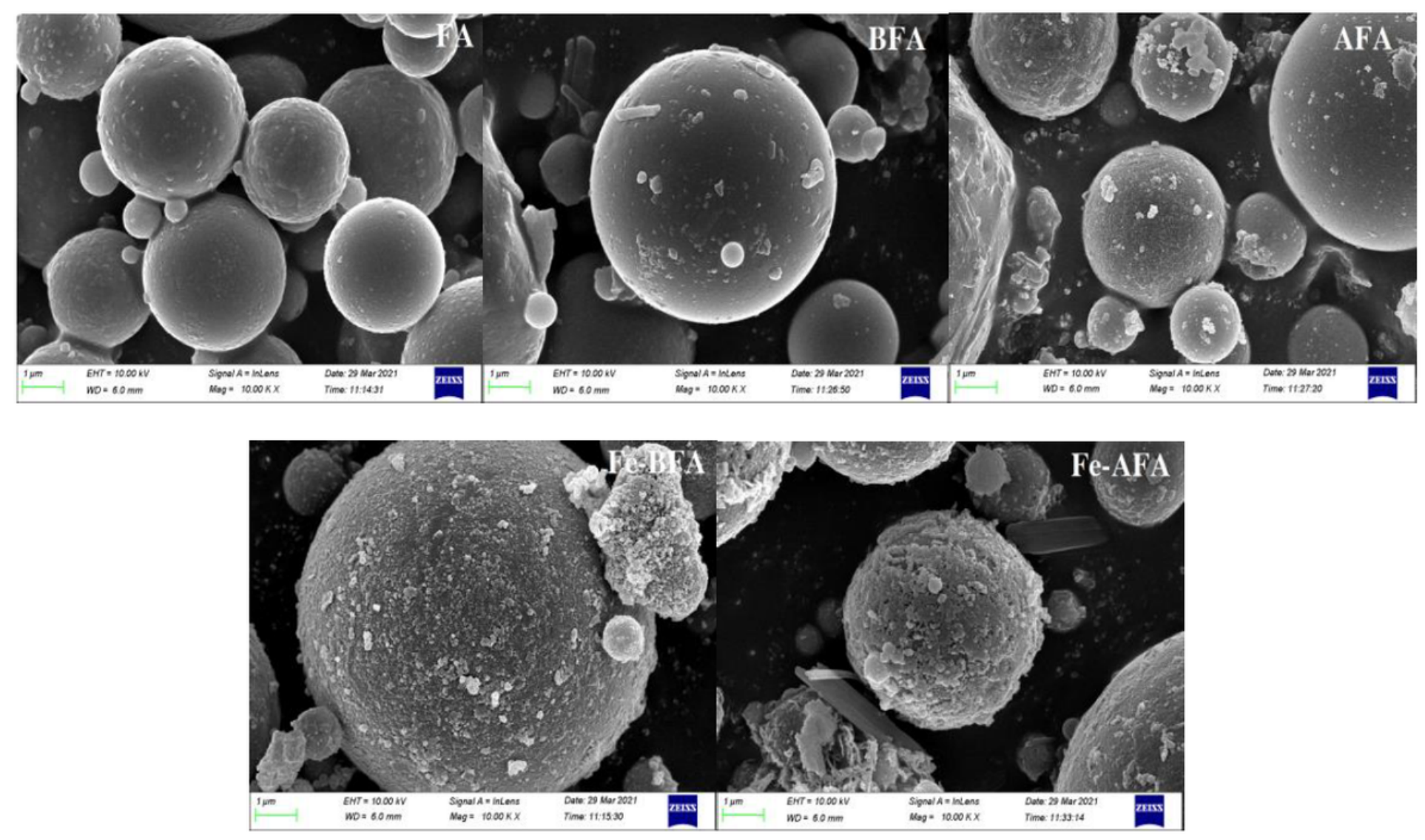

Figure 1

SEM diagrams of FA, BFA, AFA, Fe-BFA and Fe-AFA 

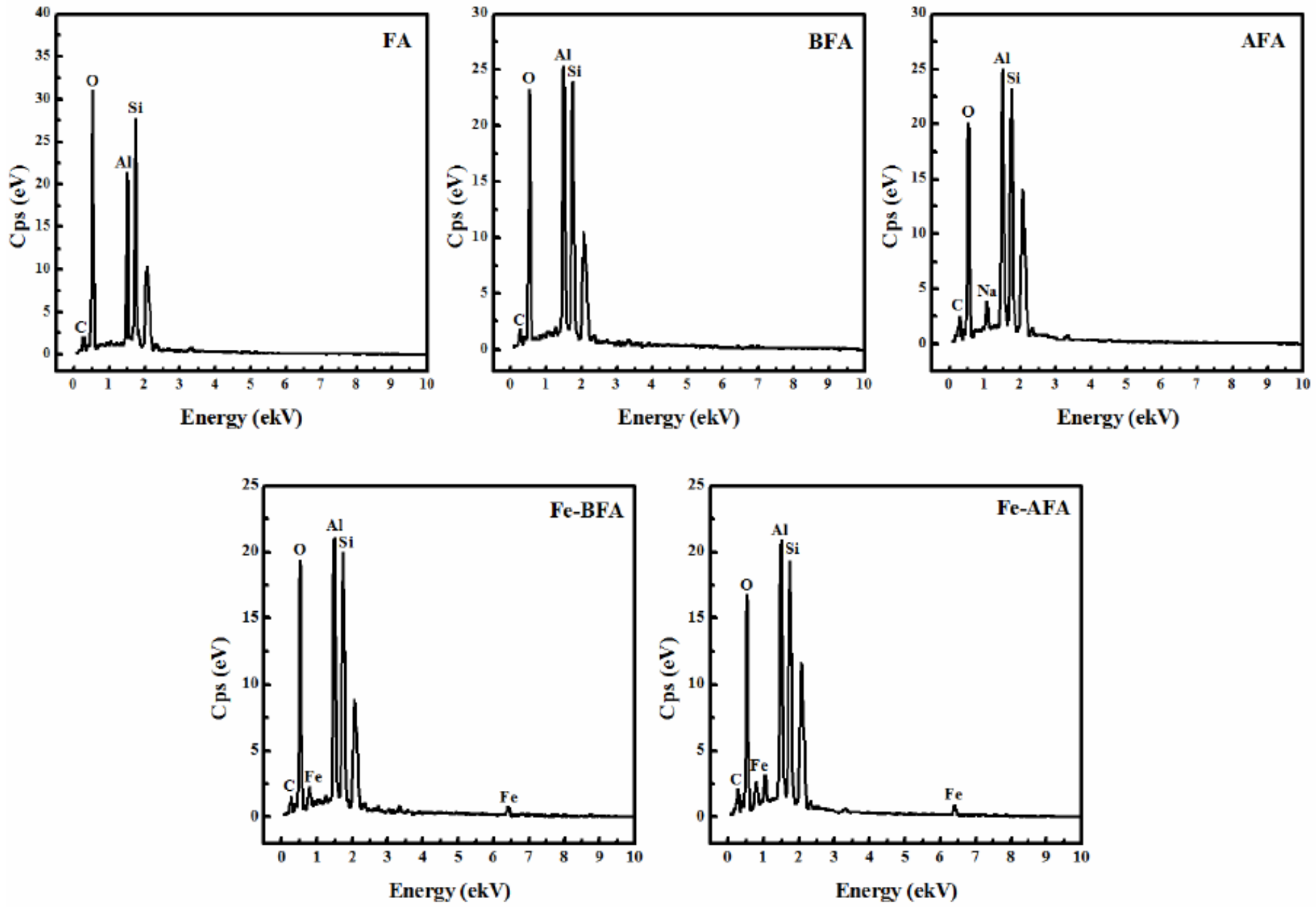

Figure 2

EDS spectra of FA, BFA, AFA, Fe-BFA and Fe-AFA 


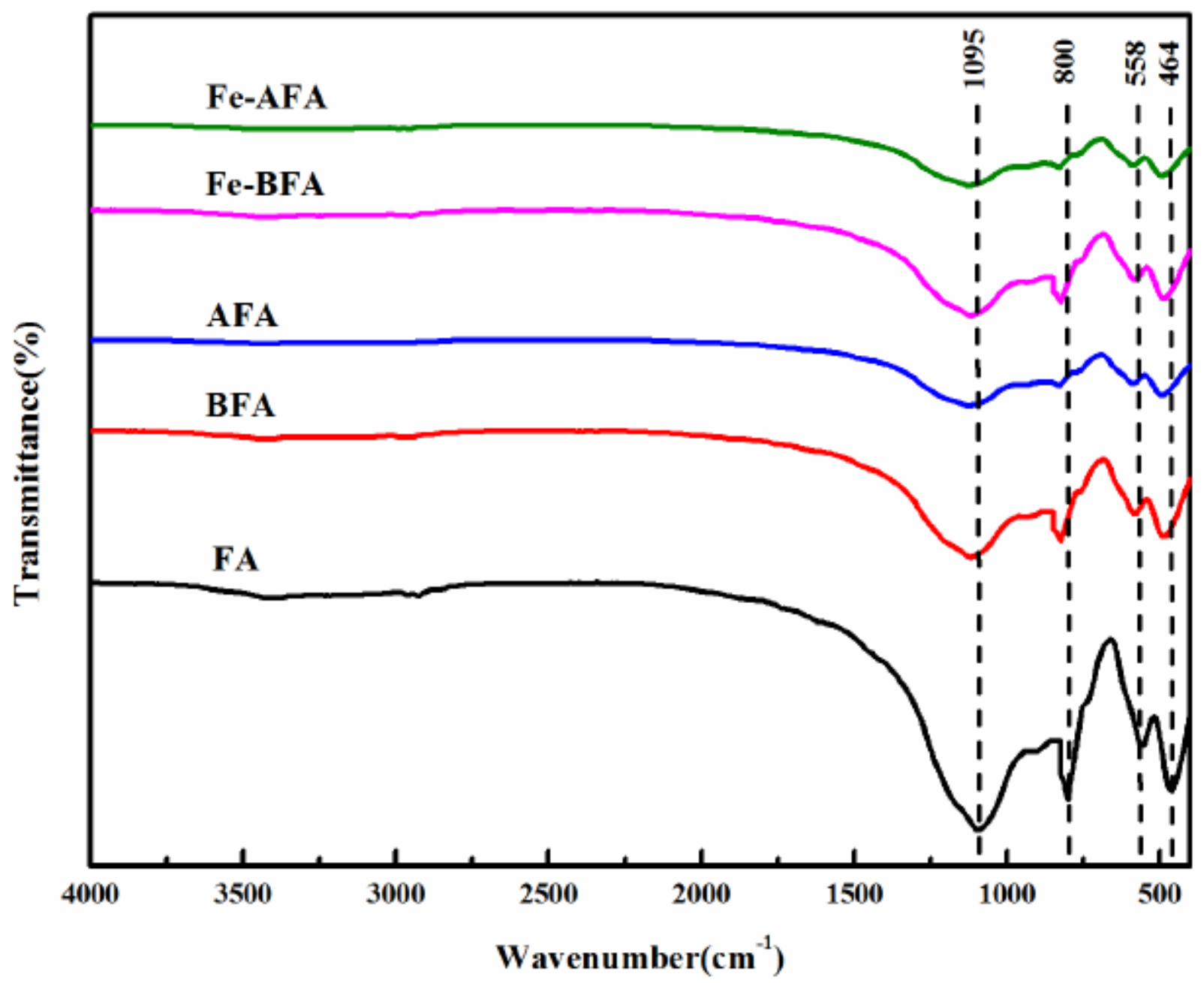

Figure 3

FTIR spectra of FA, BFA, AFA, Fe-BFA and Fe-AFA
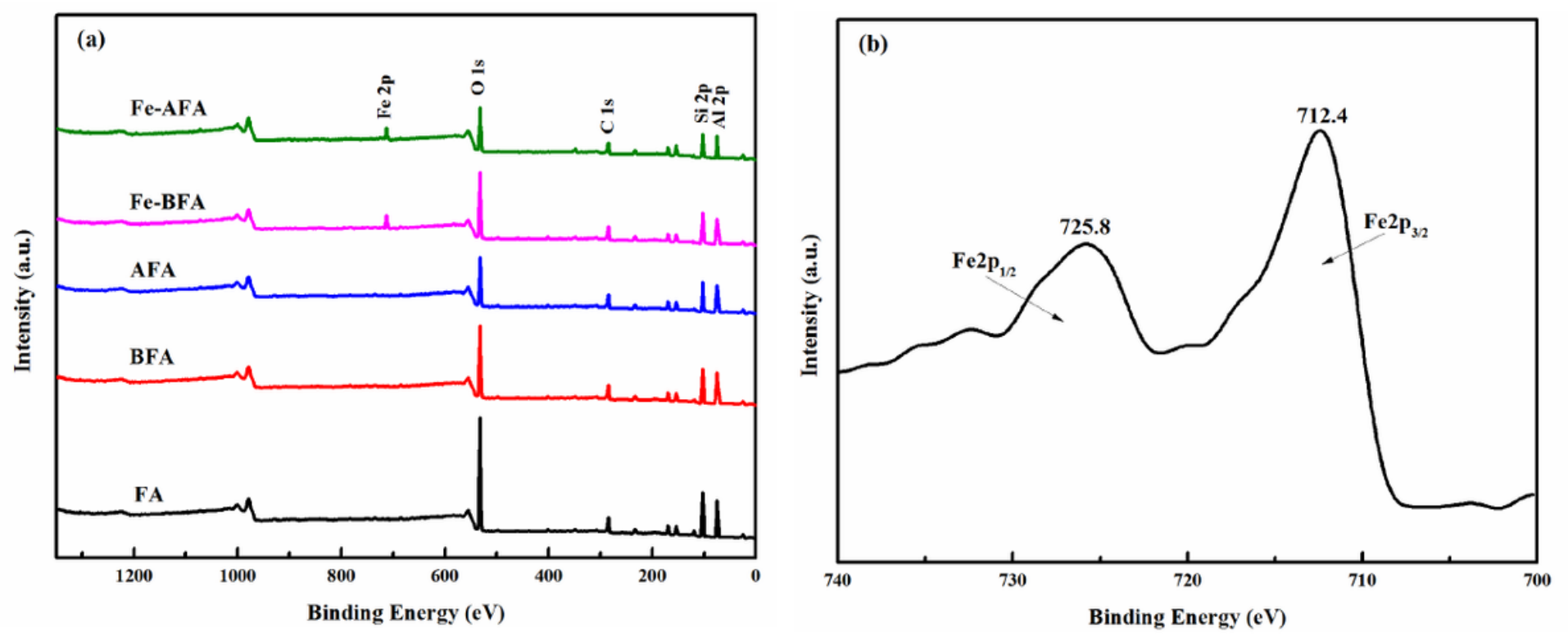

Figure 4 
XPS spectra of FA, BFA, AFA, Fe-BFA and Fe-AFA (a) and fine spectra of Fe2p peak (b)

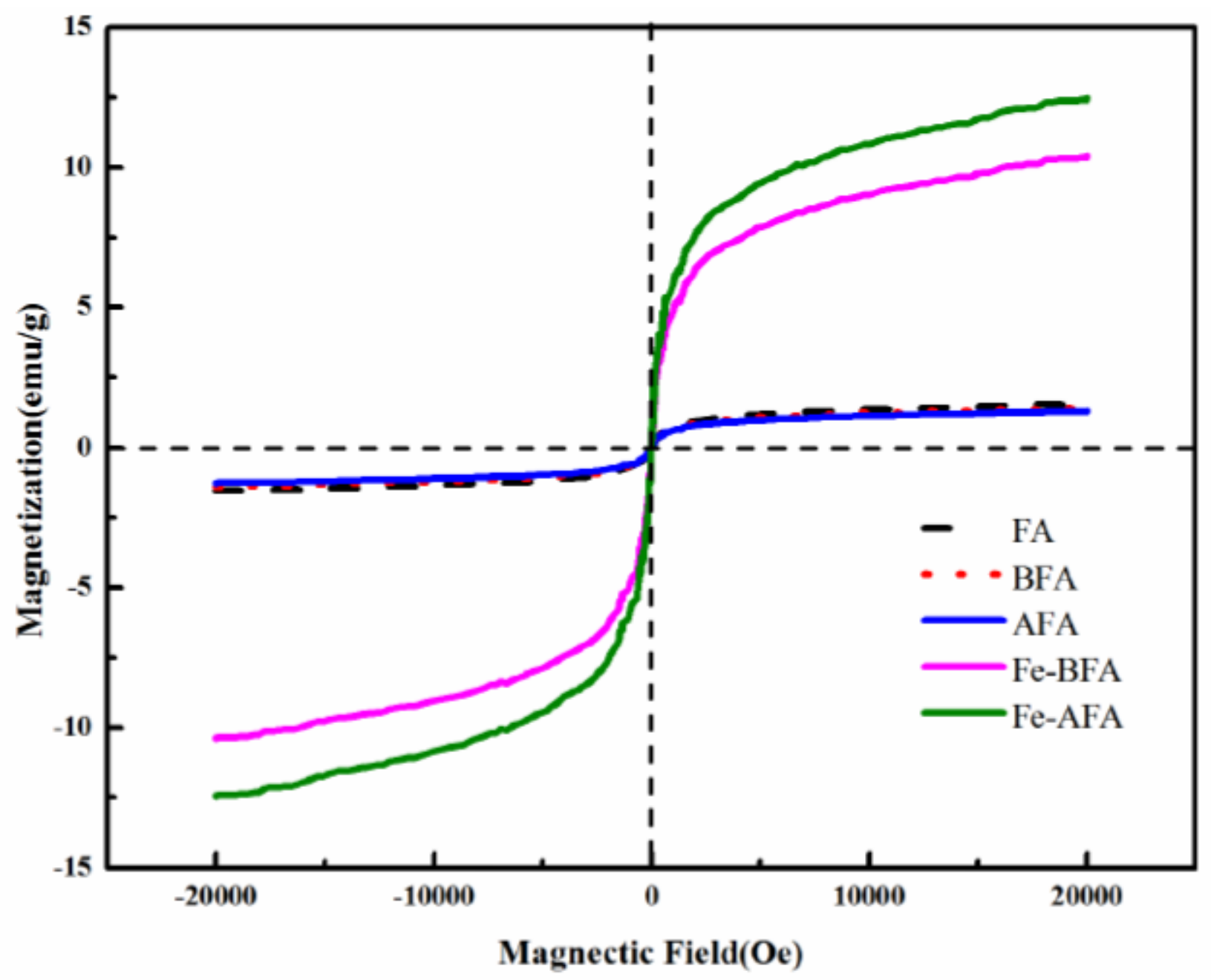

Figure 5

VSM curves of FA, BFA, AFA, Fe-BFA and Fe-AFA 


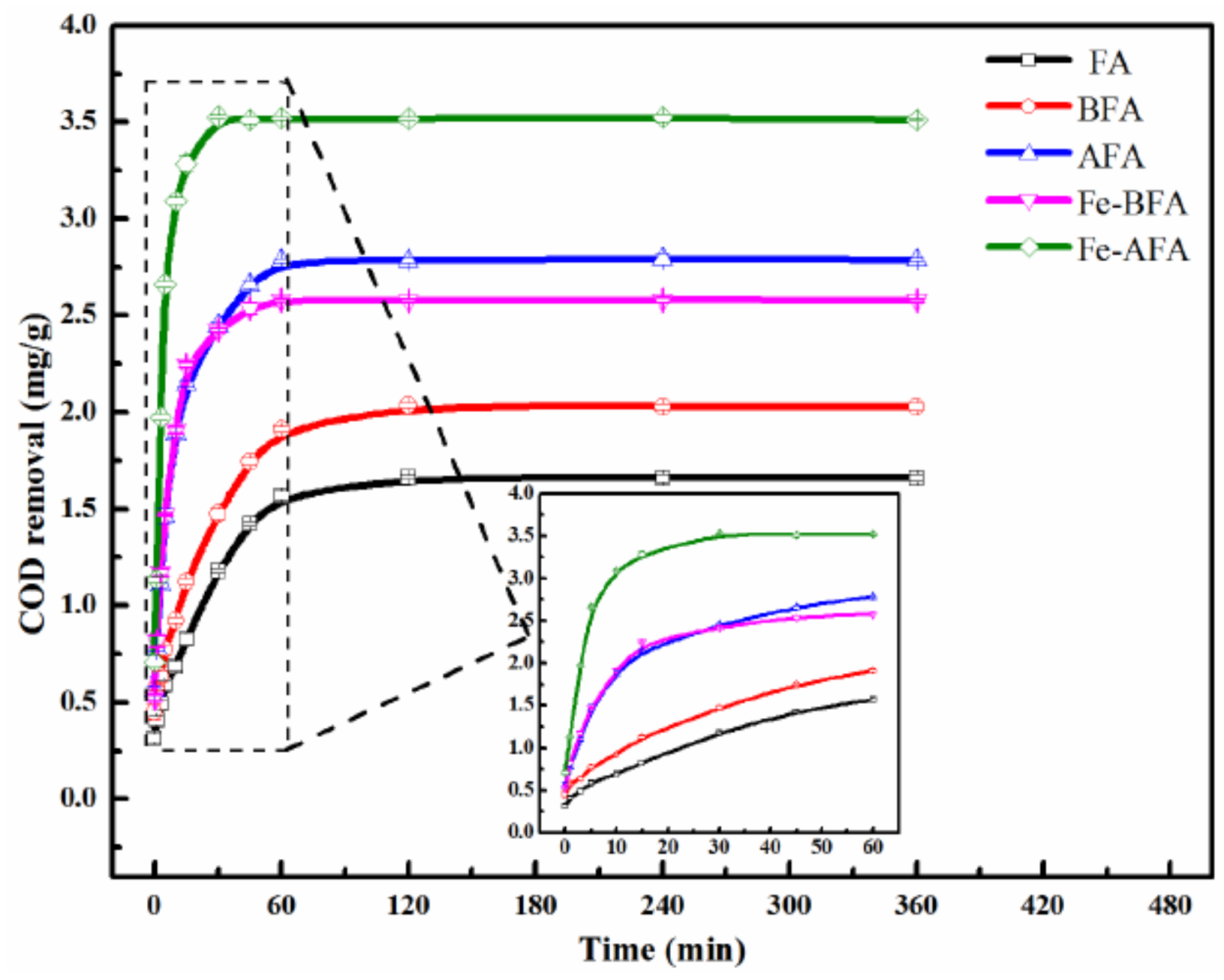

Figure 6

Coagulation kinetics curves of COD removal by FA, BFA, AFA, Fe-BFA and Fe-AFA 


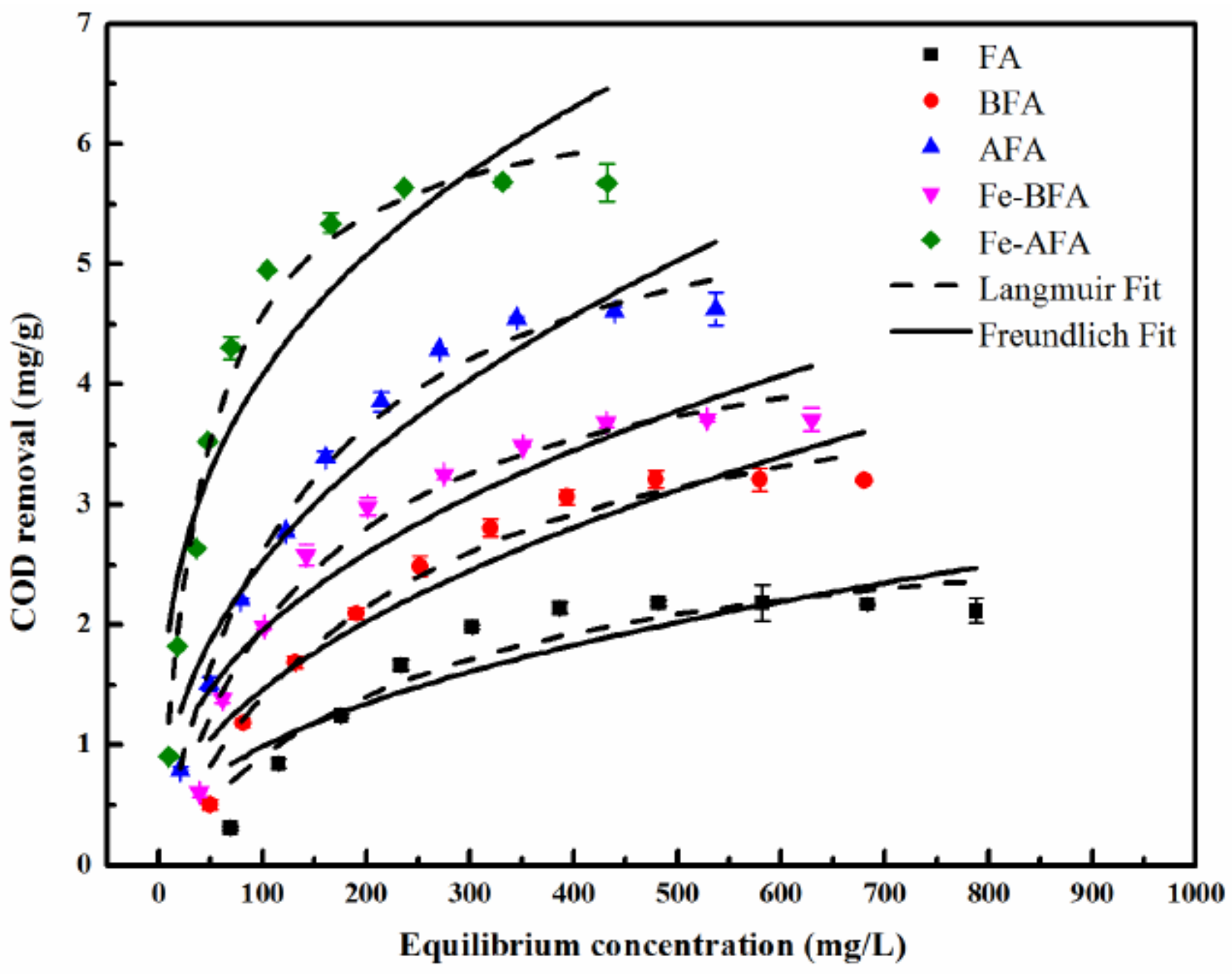

Figure 7

Coagulation isotherm curve of COD removal by FA, BFA, AFA, Fe-BFA and Fe-AFA 


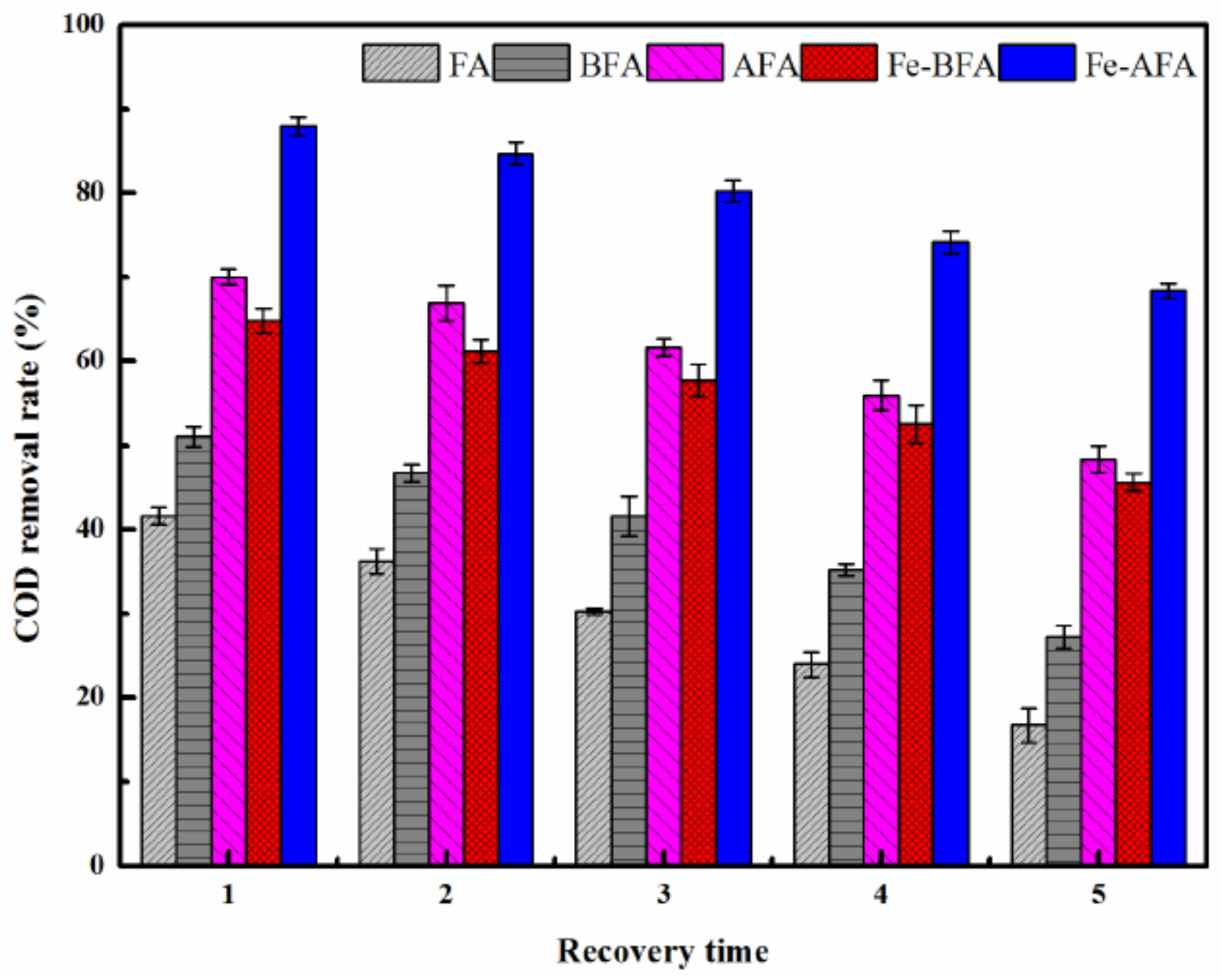

Figure 8

Effect of recovery times on COD removal efficiency by FA, BFA, AFA, Fe-BFA and Fe-AFA 